\title{
Francisco de Asís en San Pietro in Montorio. Los frescos de la Real Academia de España
}

\author{
CANALDA LLOBET, Silvia
}

Ministerio de Asuntos Exteriores, Unión Europea y Cooperación, Madrid, 2019

ISBN: 109-19-109-5

\section{FRANCISCO DE ASÍS en SAN PIETRO IN MONTORIO}

Los frescos de la Real Academia de España Sílvia Canalda Llobet

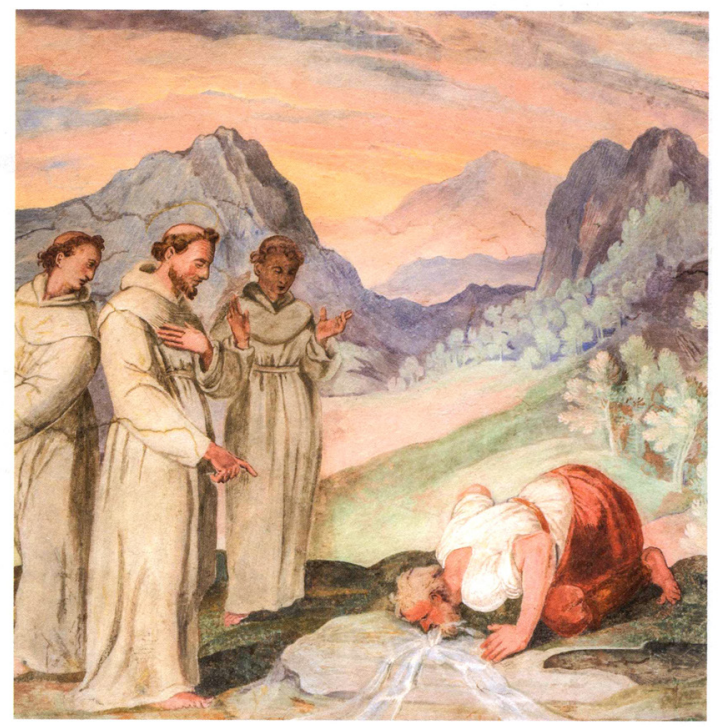

Ser residente de la Academia de España en Roma, ubicada desde hace tiempo en un antiguo convento franciscano de la ciudad, tiene, sin lugar a dudas, toda una serie de atractivos: por un lado, disfrutar de un marco excepcional en el que llevar a cabo un soggiorno de investigación o período de formación artístico; y, por otro, vivir entre los muros de San Pietro in Montorio y dejarte llevar por un entorno que habla del Cinquecento italiano y que, sin saberlo, una parte del mismo puede convertirse con el tiempo en un tema específico de estudio y análisis. La Dra. Sívia Canalda ha tenido el privilegio de conseguir ambas cosas, primero como becaria del Ministerio de Asuntos Exteriores español con motivo de puntuales aspectos relacionados con su tesis doctoral; $y$, segundo, al centrar su atención en el ciclo de la vida y milagros de san Francisco de Asís, pictóricamente representado al fresco en las cuatro crujías del claustro interior y en el patio del Templete -también conocido como primer claustrorealizado por Bramante dentro del marco arquitectónico del edificio religioso.

El recorrido del estudio de las pinturas realizadas por II Pomarancio e il Lombardelli a finales del siglo XVI ha sido progresivo, pero también exigente e intenso. El obligado sorteo de dificultades varias, entre ellas la dispersión de las fuentes primarias y la más que posible pérdida del archivo primitivo de San Pietro in Montorio, ha quedado subsanado por la autora con pacientes horas en centros de investigación romanos y foráneos en la consulta de documentos que le permitiesen reconstruir el programa pictórico franciscano. Desde esta perspectiva, su trabajo no solamente llena un importante hueco temático en las estanterías de bibliotecas especializadas en Historia del Arte y en las de tantos y tantos docentes centrados en la etapa del Alto Renacimiento, sino que, desde un punto de vista bibliográfico, se trata del primer libro de carácter monográfico que habla de tú a tú con las pinturas bajo la estricta disciplina de la iconografía.

En un tema de investigación de esta envergadura, al que se han aproximado de manera parcial algunos historiadores a lo largo de las últimas décadas, eran muchas las incógnitas que quedaban por resolver. Nada sorprendente, por otra parte, cuando se trata de dar respuesta a intereses de carácter religioso, histórico y artístico. De esta forma, y tras el preceptivo estado de la cuestión en torno a las monografías existentes vinculadas a la decoración pictórica, la Dra. Canalda desgrana, a lo largo de varios capítulos, complicadas cuestiones relacionadas con el comitente, la realidad de los franciscanos y del papado en la época, las 
fuentes, el orden de la ejecución de los frescos y su ubicación así como la intencionalidad de los mismos.

Son varios los personajes que, dentro de este proceso, salen del anonimato y recuperan su papel protagonista. Entre ellos Costanzo Torri -también conocido como Costanzo Boccafuoco-, primer cardenal titular de San Pietro in Montorio por decisión de Sixto V (1587). Con este nombramiento, y siguiendo la línea de estudio precedente de Jack Freiberg, el pontífice extendió su autoridad hacia un lugar hasta entonces asociado a la corona española. Importante recordar que la construcción de la iglesia y del Tempietto fue financiada por los Reyes Católicos, con este último como símbolo cristiano de vital importancia porque su emplazamiento se corresponde al lugar donde, según la tradición, san Pedro había sido crucificado. El conflicto estaba servido. En esta voluntad de ampliación del poder papal, la figura de Boccafuoco, probable ideólogo del ciclo pictórico, se convierte en un eslabón de la política pontificia. Fuentes visuales y literarias, hasta ahora inéditas, han permitido a la autora sustentar la afirmación de que Sixto V, a través de su cardenal, hizo valer su filosofía franciscana como medio de adoctrinar a los creyentes. No por casualidad, los milagros de san Francisco de Asís están representados en el patio del Templete, es decir, el de más fácil acceso al recinto por la población.

En este marco cabe entender también la circunstancia de la antigua dispensa en forma de indulgencia a quienes visitaban el recinto martirial, lucro por entonces de la comunidad franciscana residente. Este episodio tiene su correspondencia o equivalente religioso, en clave visual, en ocho de los nueve frescos de la galería meridional del claustro de la Academia -el ya citado claustro interior- en la que se representó la concesión milagrosa de un privilegio de idéntico talante en la iglesia conocida como de la Porciúncula. Allí, Francisco de Asís escuchó por primera vez el Evangelio y convivió con los miembros de su primitiva fraternidad. Intencionado o no, la realidad del posible vínculo entre ambas indulgencias aporta la idea de un itinerario continuo pero de dos diferentes momentos.

Establecer la línea evolutiva del programa iconográfico tampoco ha sido un proceso fácil, a pesar de los testimonios documentales y ejemplos precedentes. Las irregularidades arquitectónicas del conjunto conventual de San Pietro in Montorio afectaron a la estructura general a causa de una construcción discontinua y accidentada en la que, sin em- bargo, el ciclo sobre la vida de san Francisco adquirió gran protagonismo al aportar al edificio una unidad de la que carecía antes de la ornamentación pictórica en forma de lunetos. Para su correcta lectura e interpretación, han resultado clave para la autora antecedentes como el de Dono Doni, responsable de la decoración del claustro del Sacro Convento de Asís (1564-1570), conocido como claustro de Sixto IV; o bien el del convento florentino de San Salvador di Ognissanti a partir de 1600, obra de Jacopo Ligozzi, mucho más cercano en cuanto a método artístico al ciclo janiculense. Aquí, la serie representada progresó en función del donativo de diversas familias nobles de la ciudad, algunas de las cuales pueden identificarse gracias a la inclusión de sus escudos en la parte baja o dentro de los frescos. Por tanto, el financiamiento colectivo, de carácter supuestamente privado, pasó a tener una dimensión pública. En un proceso parecido, Ludovico da Modena, cronista de la Observancia franciscana, relacionó con los comitentes de las pinturas de San Pietro in Montorio la existencia de escudos en la parte inferior de los lunetos a través de una referencia previa en varias fuentes documentales.

Imposible, actualmente, restituir sus armas o imaginar su configuración primigenia junto a las inscripciones que les acompañan debido a la escasez de los restos conservados. Por tanto, una de las conclusiones a las que llega el lector interesado en este singular tema artístico va más bien en función de una visión de conjunto: belleza, didáctica, devoción y propaganda se hermanan en la justificación de estas series pictóricas. Se observa, sin embargo, y como acertadamente subraya la Dra. Canalda, la intención de dar un paso al frente. Del ejemplo del fundador como modelo a seguir, se pasó a los nuevos referentes de santidad contrarreformista a modo de reflejo de la sociedad de entonces y de los problemas más urgentes de la iglesia de Roma. Los tiempos habían cambiado.

El papel protagonizado por unas fuentes visuales muy precisas es el argumento principal del último capítulo del libro. La autora propone aquí un ejercicio comparativo de imágenes entre los frescos de San Pietro in Montorio y tres series distintas de grabados que fueron editadas en Roma a finales del siglo XVI y primeros años del XVII por Francesco Villamena y Philippe Thomassin. Así, al margen de constatar que el hecho por sí mismo denota un elevado uso devocional del programa iconográfico de san Francisco de Asís y un 
marcado interés comercial, las láminas, publicadas respectivamente en 1594, 1603 y 1608, representan, cuando se puede establecer una similitud, un punto de apoyo razonable para secuenciar el ritmo de ejecución de los lunetos y la intervención incluso de los pintores, mientras que, las diferencias, llevan a argumentar esta circunstancia por caminos diferentes.

Más allá de todo cuanto la reflexión de la Dra. Canalda nos aproxima hoy en día a los frescos pintados en San Pietro in Montorio, hay que valorar no tan solo la dificultad de afrontar con una mirada transversal muchos de los acontecimientos complicados de la época a través de la consulta de una bibliografía específica, fuentes visuales y material inédito, sino también el justo equilibrio entre divulgación y la apertura de nuevas líneas de investigación. Fundamental, en este caso, para una historiadora del arte que no da por con- cluido uno de los episodios que mejor explica el porqué de una decoración, qué momento de la historia lo acompaña y que, además, articula en su discurso a todos los protagonistas relacionados con el tema. Su intención es, por tanto, profundizar aún más en el desarrollo del ciclo pictórico y exponer y divulgar las teorías en revistas especializadas. El actual plan de conservación y puesta en valor del complejo de San Pietro in Montorio por parte de la AECID (Agencia Española de Cooperación Internacional para el Desarrollo) impulsará, sin duda, que libros como este sean el punto de partida del estudio de complejos programas iconográficos u otro tipo de obras en los que historia y religión se unan para dar al arte un papel protagonista.

Laura García Sánchez Universidad de Barcelona 